\title{
Sensitivity of carboxyl-modified carbon nanotubes to alkaline metals
}

\author{
N. P. Boroznina, I. V. Zaporotskova, S. V. Boroznin \\ Volgograd State University, Universitetskii prospect, 100, 400062 Volgograd, Russia \\ polikarpova.natalya@volsu.ru, irinazaporotskova@gmail.com
}

PACS 85.35.Kt

DOI 10.17586/2220-8054-2018-9-1-79-84

\begin{abstract}
This paper considers the fabrication of a superminiaturized sensor based on carboxyl-modified carbon nanotubes. The possibility of using nanotubes modified by carboxyl group for detection of alkaline metals is analyzed. Simulation results have been reported for the binding process of carboxyl group to the nanotube surface and interaction of the nanosystem fabricated with atoms of potassium, sodium and lithium. The simulation has been carried out using the molecular cluster model and the MNDO and DFT calculation methods. Sensor properties of surface and boundary carboxyl-modified nanotubes for alkaline metals have been compared. It has been proved that surface carboxyl-modified nanotubes are characterized by higher sensitivity for the selected atoms.
\end{abstract}

Keywords: carbon nanotubes, sensor properties, sensors on the basis of carbon nanotubes, boundary modified nanotubes, surface-modified nanotubes, carboxyl group.

Received: 20 June 2017

Revised: 25 October 2017

\section{Introduction}

The discovery of carbon nanotubes (1D nanostructures) is one of the most important achievements of modern science. Considered as a new material with unique physicochemical properties, nanotubes show good promise for a wide range of applications [1-6]. Nanotubes can be used in flat displays, lithium battery anodes, gas discharge tubes in telecommunication networks, nanoprobes and sensors, supercapacitors, gas storage, etc. [7,8]. Nanotube-based systems display a combination of multiple properties that cannot be achieved in conventional single crystal and polycrystalline structures, so the current stage of research into the nanotubular forms of materials is characterized by a great interest in development and improvement of their synthesis methods, study of the properties of these nanomaterials and attempts for their commercial applications.

As a nanotube is a surface structure, its whole weight is concentrated in its surface layers. This feature is the origin of the uniquely large unit surface of tubulenes which in turn predetermines their electrochemical and adsorption properties $[9,10]$. The high sensitivity of the electronic properties of nanotubes to molecules adsorbed on their surface and the unparalleled unit surface providing for this high sensitivity make CNT a promising starting material for the development of superminiaturized chemical and biological sensors [11-20]. The operation principle of these sensors is based on changes in the V-I curves of nanotubes as a result of adsorption of specific molecules on their surface. The use of CNT in sensor devices is one of their most promising applications in electronics. These sensors should have high sensitivity and selectivity, as well as rapid response and recovery.

The paper studies the possibility for fabricating superminiaturized high-sensitivity sensor based on carboxylmodified carbon nanotube and analyzes the process of the sensor interaction with alkaline metal atoms (sodium, potassium and lithium). Two variants of nanotube modification with the carboxyl group are considered, namely the boundary and surface binding of the $-\mathrm{COOH}$ group, and a comparative analysis of the sensor properties that takes into account location of the carboxyl group binding to the CNT is carried out. Simulation results for a carboxyl group binding process to a carbon nanotube and the system's interaction with the selected potassium, sodium and lithium ions are obtained within the framework of the molecular cluster model using the DFT calculation method [21].

\section{The study of the mechanism of nanotube modification with carboxyl group $-\mathrm{COOH}$ binding to the nanotube surface}

The mechanism for the boundary functionalization of a nanotube by a carboxyl group is reported in [22]. The present paper studies the mechanism for nanotube surface modification with carboxyl group -COOH. A model of a nanotube of type $(6,0)$ molecular cluster is considered. The cluster contained five layers of carbon hexagons located along the axis of the nanotube. The cluster boundaries were closed by pseudoatoms of hydrogen. The carboxyl group bound a carbon atom located on a surface site approximately in the middle of the cluster to exclude 
the effect of pseudoatoms. The mechanism of the functional group - $\mathrm{COOH}$ binding to the selected atom was modeled with increment of $0.1 \AA$ along a perpendicular that was drawn to the axis of the nanotube and passed through the selected carbon atom of the surface. The calculations were carried out using the DFT method. Fig. 1 shows a model of surface-modified carbon nanotube $(6,0)$ with carboxyl group. The performed calculations enabled us to plot an energy interaction curve (Fig. 2), the analysis of which shows that a value of interaction energy between the CNT and the carboxyl group is $183 \mathrm{eV}$. This value indicates the formation of chemical bond between the nanotube and $-\mathrm{COOH}$ at the distance of $166 \AA$ that proves the possibility of surface functionalization of single-walled carbon nanotubes with a carboxyl group to fabricate chemically active sensory probes.

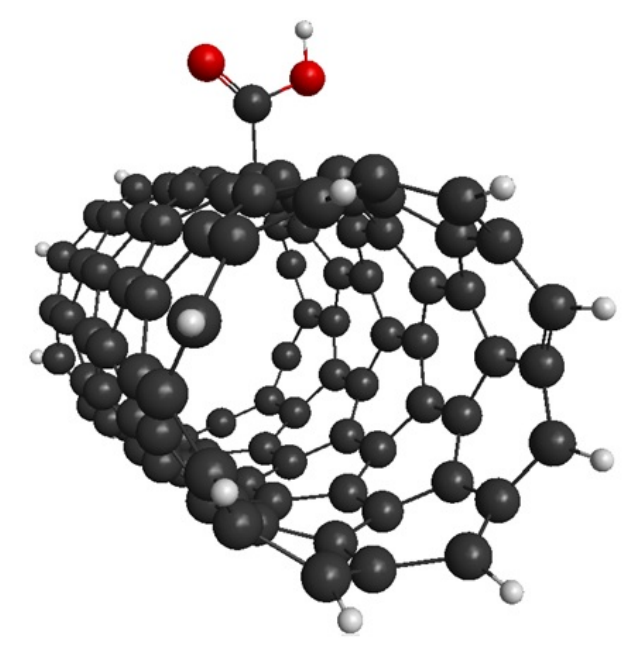

FIG. 1. Model of carbon nanotube with surface modified by carboxyl group

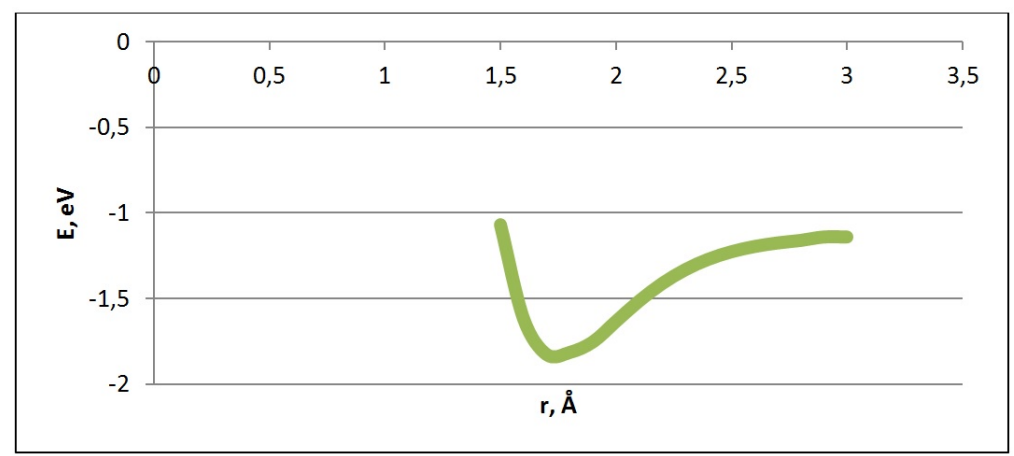

FIG. 2. Interaction energy curve of CNT with carboxyl group

\section{Study of interaction between the "CNT-carboxyl group" system and atoms of alkali metals}

Further, interaction of lithium, sodium, and potassium atoms with the edge atoms of hydrogen and oxygen in the carboxyl group modifying the carbon nanotube surface was studied. The process is modeled incrementally by moving alkaline metals $(\mathrm{Na}, \mathrm{K}, \mathrm{Li})$ towards $\mathrm{O}$ or $\mathrm{H}$ atoms of the functional group. As a result, profiles of potential energy surface of the system "nanotube $+\mathrm{COOH}-m e t a l$ atom" are plotted (Fig. 3). Simulation results reveal barrier-free nature of the selected metal atoms binding process to the atoms of the functional group. As the interaction distances are sufficiently large, it can be concluded that the functional group atoms and the selected metal atoms are held together by weak van der Waals forces. This result confirms the possibility of reusing the fabricated sensor probe, as chemical bond formation with the selected alkaline metal atoms would have caused destruction of the fabricated sensor. In addition, the Schottky barrier between the "nanotube + COOH" system and the electrodes of the sensor can vary during the interaction process with metal atoms, which will be recorded during the sensor operation. 

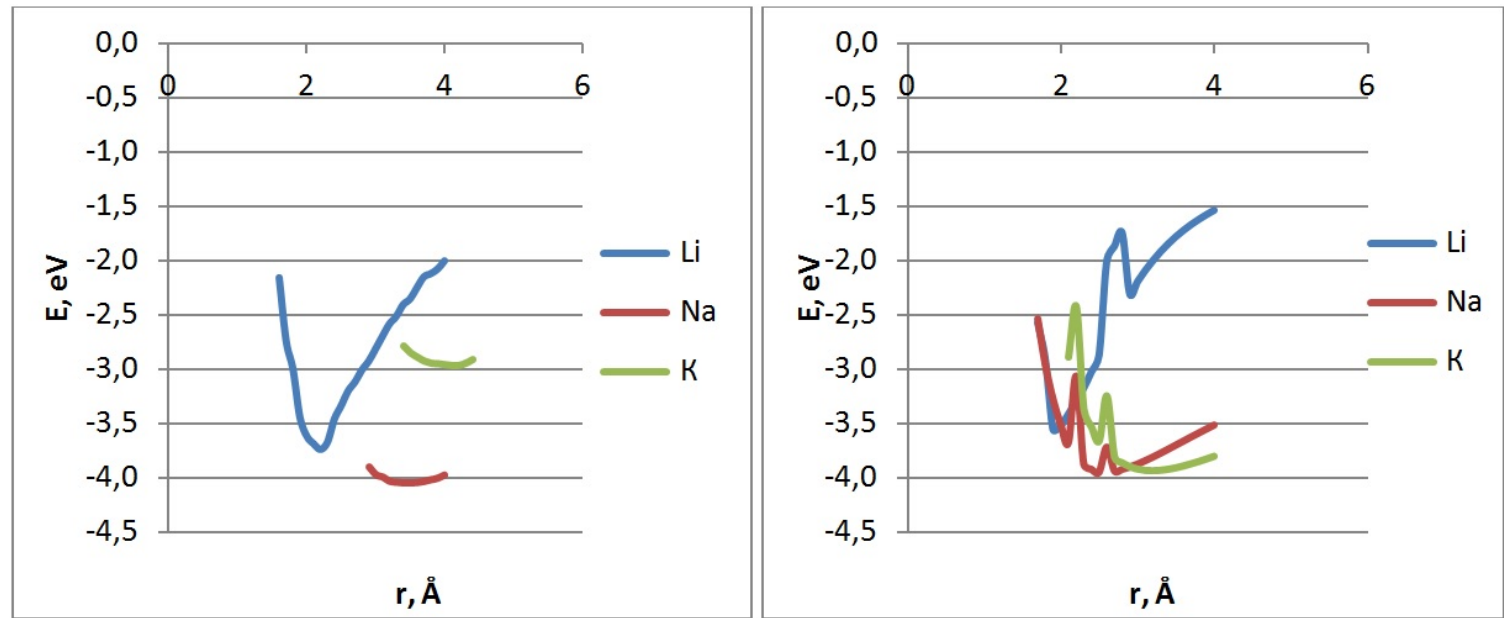

FIG. 3. Energy curves plotted for surface modified by carboxyl group nanotube interaction with $\mathrm{Li}, \mathrm{Na}, \mathrm{K}$ atoms depending on a distance: a - between atoms of selected metals and an $\mathrm{H}$ atom of the system; $\mathrm{b}$ - between atoms of selected metals and an $\mathrm{O}$ atom of the system

Analysis of the charge state of the system revealed that electron density is transferred from the metal atoms to a surface-modified by carboxyl group nanotubular system, which increases the number of carriers in the system and ensures a change in its electrical properties.

Simulation results for interaction between the boundary modified by carboxyl group carbon nanotube $(6,0)$ and $\mathrm{Na}, \mathrm{K}, \mathrm{Li}$ atoms of alkaline metals are presented in [23]. Table 1 summarizes the interaction results of the selected atoms with surface- and boundary-modified by carboxyl group CNTs.

TABLE 1. Main characteristics of the binding process of $\mathrm{Na}, \mathrm{K}, \mathrm{Li}$ atoms to the edge $\mathrm{O}$ and $\mathrm{H}$ atoms of carboxyl group boundary and surface modifying the carbon nanotube: $r_{\text {int }}$ - interaction distance between a metal atom and an $\mathrm{O}($ or $\mathrm{H})$ atom of the functional, $E_{\text {int }}$ - interaction energy

\begin{tabular}{|l|c|c|c|}
\hline Atom bonds & $r_{\text {int }}, \AA$ & $E_{\text {int }}, \mathrm{eV}$ & $\begin{array}{c}\text { Charge on the } \\
\text { metal atoms }\end{array}$ \\
\hline \multicolumn{4}{|c|}{ Boundary-modified nanosystem } \\
\hline $\mathrm{Na}-\mathrm{O}$ & 2.2 & -3.21 & +0.7 \\
\hline $\mathrm{Na}-\mathrm{H}$ & 1.8 & -1.77 & +0.7 \\
\hline $\mathrm{K}-\mathrm{O}$ & 2.5 & -4.30 & +0.4 \\
\hline $\mathrm{K}-\mathrm{H}$ & 1.8 & -1.04 & +0.4 \\
\hline $\mathrm{Li}-\mathrm{O}$ & 2.0 & -4.39 & +0.9 \\
\hline $\mathrm{Li}-\mathrm{H}$ & 1.9 & -4.62 & +0.9 \\
\hline \multicolumn{5}{|c|}{ Surface-modified nanosystem } \\
\hline $\mathrm{Na}-\mathrm{O}$ & 3.0 & -2.57 & +0.7 \\
\hline $\mathrm{Na}-\mathrm{H}$ & 3.4 & -2.70 & +0.7 \\
\hline $\mathrm{K}-\mathrm{O}$ & 4.2 & -2.12 & +0.4 \\
\hline $\mathrm{K}-\mathrm{H}$ & 4.1 & -1.57 & +0.4 \\
\hline $\mathrm{Li}-\mathrm{O}$ & 1.9 & -3.92 & +0.9 \\
\hline $\mathrm{Li}-\mathrm{H}$ & 2.2 & -2.43 & +0.9 \\
\hline
\end{tabular}




\section{Modeling scanning of surface with atoms of alkaline metals}

Scanning of a random site on the nanotube surface that contains $\mathrm{Li}, \mathrm{Na}$ or $\mathrm{K}$ atoms is performed and sensitivity of the nanotube modified by carboxyl group to the atoms selected is defined. The process was modeled incrementally by moving a metal atom to the functional group along the line parallel to the nanotube surface (Fig. 4). Analysis of interaction energy curves (Fig. 5) shows that the modified nanotube is sensitive to the selected metals as the curve has a minimum that indicates a stable interaction of metal atoms with the "CNT $+\mathrm{COOH}$ " system.

Simulation results of sensor activity for a boundary modified by a carboxyl group nanotube are presented in [23]. Table 2 summarizes the results of the interaction for sensor based on surface- and boundary-modified by carboxyl group nanotubes with atoms of the selected metals. A comparison of the interaction energies $\mathrm{E}_{\text {int }}$ shows that the surface-modified by the $\mathrm{COOH}$ group nanotubular system display higher sensitivity for the selected potassium, lithium and sodium atoms.
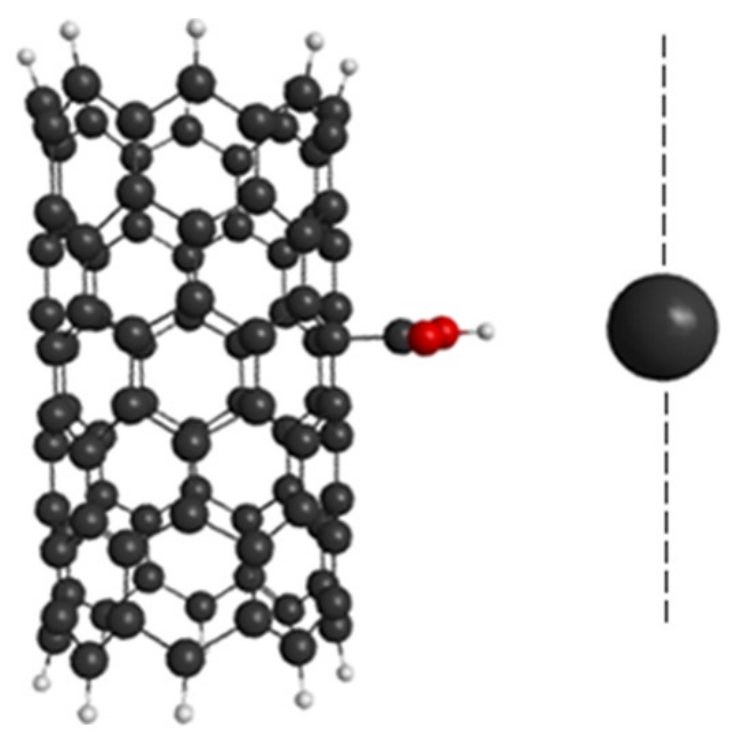

FIG. 4. Scanning of a random site on the nanotube surface that contains Li atom (a grey ball of a bigger size); the dotted line indicates the trajectory of the Li atom in relation to the nanotube modified by carboxyl group

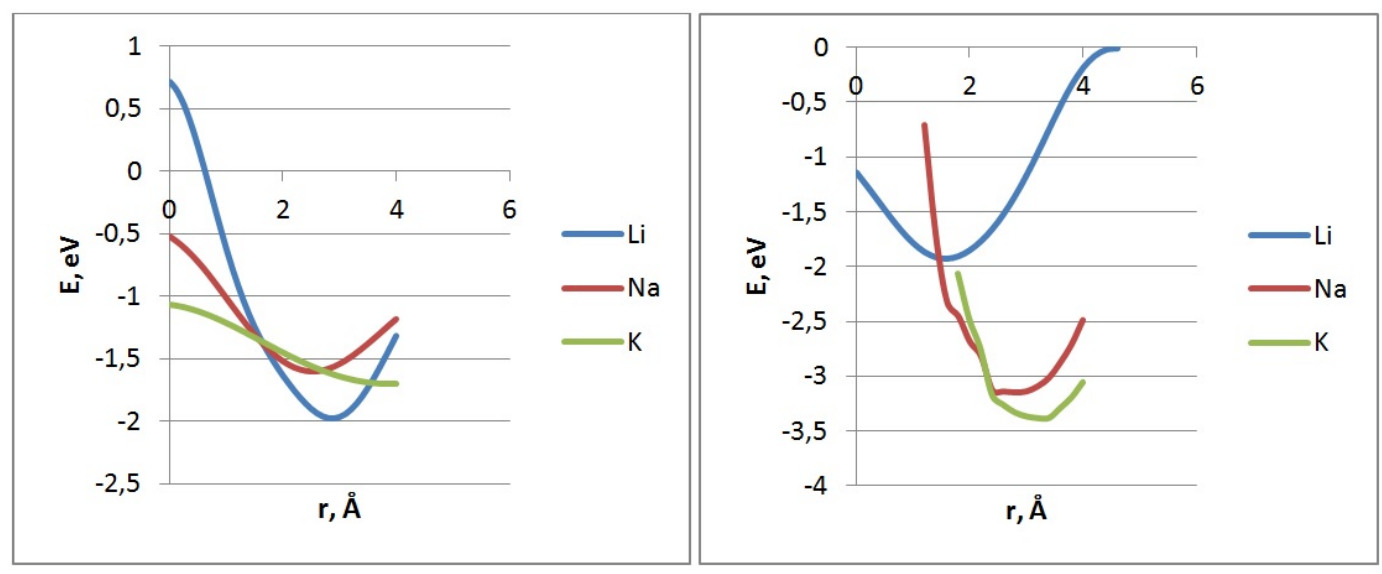

FIG. 5. Interaction energy profiles plotted for atoms of metals and a surface modified nanotubular structure; 0 point corresponds to the point located under atom $\mathrm{H}$ of carboxyl group, as well as one of atoms $\mathrm{H}$ of amino group and atom $\mathrm{O}$ of nitrogroup: a) with $\mathrm{H}$ atom $\mathrm{b}$ ) with $\mathrm{O}$ atom 
TABLE 2. Interaction characteristics between the boundary-modified by carboxyl group nanotube system and $\mathrm{Na}, \mathrm{K}$, Li atoms: $r_{\text {int }}$ - sensor interaction distance, $E_{\text {int }}$ - sensor interaction energy

\begin{tabular}{|c|c|c|}
\hline Atom (group - $\mathrm{COOH}$ ) & $r_{n t}, \AA$ & $E_{i n t}, \mathrm{eV}$ \\
\hline \multicolumn{3}{|c|}{ Boundary-modified nanostem } \\
\hline $\mathrm{Na}-\mathrm{O}$ & 3.0 & -0.64 \\
\hline $\mathrm{Na}-\mathrm{H}$ & 2.6 & -1.73 \\
\hline $\mathrm{K}-\mathrm{O}$ & 2.5 & -1.77 \\
\hline $\mathrm{K}-\mathrm{H}$ & 2.8 & -1.76 \\
\hline $\mathrm{Li}-\mathrm{O}$ & 3.0 & -0.93 \\
\hline $\mathrm{Li}-\mathrm{H}$ & 3.0 & -1.63 \\
\hline \multicolumn{3}{|c|}{ Surface-modified nanosystem } \\
\hline $\mathrm{Na}-\mathrm{O}$ & 3.0 & -3.38 \\
\hline $\mathrm{Na}-\mathrm{H}$ & 3.4 & -4.05 \\
\hline $\mathrm{K}-\mathrm{O}$ & 4.2 & -3.75 \\
\hline $\mathrm{K}-\mathrm{H}$ & 4.1 & -3.00 \\
\hline $\mathrm{Li}-\mathrm{O}$ & 1.9 & -4.00 \\
\hline $\mathrm{Li}-\mathrm{H}$ & 2.2 & -3.74 \\
\hline
\end{tabular}

\section{Conclusion}

As theoretical and experimental studies have shown, carbon nanotubes present a unique material for further research and application in various fields. Advancement in nanotechnology leads to fabrication of new physical objects with properties that are of great scientific and research interest. The proven possibility of carbon nanotube modification by a carboxyl group can be used to create probes with high selectivity. Simulation results prove the possibility of repeated use of modified carbon nanotubes as sensor probes for certain elements and radicals. The presence of these elements and radicals can be experimentally documented by changing the potential in a sensor system based on a nanotube modified by a functional group. When the fabricated sensor interacts with metal atoms, electron density is transferred to the atoms of the carboxyl nanotubular system. Thus, the number of carriers in the surface modified nanotube system increases and a change in the electrical properties of the nanosystem can be fixed. The fabricated sensor element will have a distinctive selectivity that is determined by the energies of the modified tubular nanosystem's interaction with various elements, which will provide a different response for the system to the presence of alkaline metal atoms. Sensors fabricated in this manner will respond to the presence of extremely small amounts of substances, namely atoms or ions of metals, which form part of salts and alkalis, which opens up their potential use in chemistry, biology, medicine, etc.

\section{References}

[1] Dresselhaus M.S., Dresselhaus G., Eklund P.C. Science of Fullerenes and Carbon Nanotubes. Academic Press, Inc., 1996,965 p.

[2] Saito R., Dresselhaus M.S., Dresselhaus G. Physical properties of carbon nanotubes. Imperial College Press, 1999,251 p.

[3] Ivanovskii A.L. Kvantovaya khimiya $v$ materialovedenii. Nanotubulyarnye formy veshchestva [Quantum chemistry in materials science. Nanotubular forms of matter]. UrORAN, Ekaterinburg, 1999, $176 \mathrm{p}$.

[4] Kharris P. Uglerodnye nanotruby i rodstvennye struktury. Novye materialy XXI veka [Carbon nanotubes and related structures. New materials of the 21-st century]. Tekhnosfera, Moscow, 2003, $336 \mathrm{p}$.

[5] Zaporotskova I.V. Uglerodnye $i$ neuglerodnye nanomaterialy i kompozitnye struktury na ikh osnove: stroenie $i$ elektronnye svoistva [Carbon and non-carbon nanotubes and composite struc-tures on their basis: structure and electronic properties]. Izd-vo VolGU, Volgograd, 2009, $490 \mathrm{p}$.

[6] Eliseev A.A., Lukashin A.V. Funktsional'nye nanomaterialy [Functional nanomaterials]. Fizmatlit, Moscow, 2010,456 p.

[7] Michael F.L. De Volder, Sameh H. Tawfick, Ray H. Baughman, A. John Hart. Carbon Nanotubes: Present and Future Commercial Applications. Science, 2013, 339(6119), P. 535-539. 
[8] Dresselhaus M.S., Dresselhaus G., Avouris. Carbon nanotubes: synthesis, structure, properties, and application. Springer-Verlag, 2000, $464 \mathrm{p}$.

[9] D’yachkov P.N. Elektronnye svoistva i primenenie nanotrubok [Electronic properties and applications of nanotubes]. BINOM. Laboratoriya znanii, Moscow, 2010, 488 p.

[10] Eletskii A.V. Sorption properties of carbon nanostructures. Phys. Usp., 2004, 47(11), P. 1119-1154.

[11] Akhmadishina K.F., Bobrinetskii I.I., Komarov I.A., Malovichko A.M., Nevolin V.K., Petukhov V.A., Golovin A.V., Zalevskii A.O. Flexible biological sensors based on carbon nanotube films. Nanotechnologies in Russia, 2013, 8(11-12), P. 721-726.

[12] Zhang Wei-De, Zhang Wen-Hui. Carbon Nanotubes as Active Components for Gas Sensors. J. Sensors, 2009, Article ID 160698, 16 p.

[13] Zaporotskova I.V., Boroznina N.P., Parkhomenko Y.N., Kozhitov L.V. Carbon nanotubes: Sensor properties. A review. Modern Electronic Materials, 2016, 2(4), P. 95-105.

[14] Barsan M.M., Ghica M.E., Brett C.M.A. Electrochemical sensors and biosensors based on redox polymer/carbon nanotube modified electrodes. Analytica Chimica Acta, 2015, 881, P. 1-23.

[15] Boyd A., Dube I., Fedorov G., Paranjape M., Barbara P. Gas sensing mechanism of carbon nanotubes: from single tubes to high-density networks. Carbon, 2014, 69, P. 417-423.

[16] Liu S.F., Lin S., Swager T.M. An organocobalt-carbon nanotube chemiresistive carbon monoxide detector. ACS Sens., 2016, 1(4), P. 354357.

[17] Im J., Sterner E.S., Swager T.M. Integrated gas sensing system of swent and cellulose polymer concentrator for benzene, toluene, and xylenes. Sensors, 2016, 16(2), P. 183.

[18] Kwona Y.J., Naa H.G., Kanga S.Y., Choib S.-W., Kimb S.S., Kima H.W. Selective detection of low concentration toluene gas using Pt-decorated carbon nanotubes sensors. Sens. Actuators B: Chem., 2016, 227, P. 157-168.

[19] Kim J., Choi S.-W., Lee J.-H., Chung Y., Byun Y.T. Gas sensing properties of defect-induced single-walled carbon nanotubes. Sens. Actuators B: Chem., 2016, 228, P. 688-692.

[20] Polikarpova N.P., Zaporotskova I.V., Boroznin S.V., Zaporotskov P.A. About using carbon nanotubes with amino group modification as sensors. J. Nano-Electron. Phys., 2015, 7(4), P. 04089.

[21] Koch W.A., Holthausen M. Chemist's Guide to Density Functional Theory. Wiley-VCH. Weinheim, 2002, P. 19-28.

[22] Polikarpova N.P., Vil'keeva D.E. Sensor activity of carbon nanotubes with a boundary functional group. Nanosci. Nanotechnol. Lett., 2013, 5(11), P. 1169-173.

[23] Polikarpova N.P., Zaporotskova I.V., Vilkeeva D.E., Polikarpov D.I. Sensor properties of carboxyl-modified carbon nanotubes. Nanosystems: Phys., Chem., Math., 2014, 5(1), P. 101-106. 